\title{
The Modification of Plinko Game to Learn Speaking for College Students
}

\author{
Isnaini Nurhaya ${ }^{1),}$ Arita Destianingsih ${ }^{2)}$ \\ ${ }^{1}$ Politeknik Negeri Bengkalis \\ ketty.aa24@gmail.com \\ ${ }^{2}$ Politeknik Negeri Bengkalis \\ arita@polbeng.ac.id
}

\begin{abstract}
Received: $23^{\text {rd }}$ November 2021| Revised: $29^{\text {st }}$ November 2021| Accepted: $27^{\text {th }}$ December 2021
Email Correspondence: ketty.aa24@gmail.com
\end{abstract}

\begin{abstract}
The purpose of this study was modifying a game as a media in teaching and learning to encourage university students in learning English especially speaking skills. The game was plinko game. In this study, the game was called plinko speaking game. A plinko speaking game was a game which used board, balls and task cards as media to play this game. This study belongs to descriptive method, which was aimed to describe the processes and the rule to play this game. Descriptive research "Is designed to provide a picture of a situation as it naturally happens". It may be used to justify current practice and make judgment and also to develop theories. In designing the product, there were several ways that in designing the product; first, preparing the equipment and the material, preparing material of the topic cards' theme, designing the board, designing the card, printing the cards, designing the ways how to play the game, doing the evaluation the product at university, and finishing the product design. The result of this study is a set of A Plinko Speaking Game that consists of a board game, 50 task cards and 10 balls of plinko speaking game.
\end{abstract}

Keywords: a plinko speaking game, speaking, board game

\section{INTRODUCTION}

Today's economy is increasing globalized. There are many developments started from global area which is many foreign businesses in each country. In order to be able to face the globalization, one of the ways is by mastering some foreign languages to communicate, especially English which is known as international language.

In the other hand, English is also the gateway to a world of knowledge, commerce, and culture; a language that gives the speaker access to the world. Therefore, English becomes the complication subject in Indonesia that is started from elementary school until university. In our country, English is still foreign language. That language has different pronunciation, grammatical and spelling with our mother tongue.

Online at https://journal.universitasbumigora.ac.id/index.php/humanitatis/

DOI : https://doi.org/10.30812/humanitatis.v8i1.1574 
Furthermore, it makes the learners face some difficulties in learning English especially in its basic skills. There are four skills in English such as, listening, reading, writing and speaking. Based on preobservation, the difficulties in learning skills come since in teaching and learning English process material and practice are not balance each other. Therefore, in learning English the teacher just focus on textbooks than practice in basic skills. The learners get some problem in learning basic skills especially, speaking skill.

Speaking is one of the most important skills in daily life. In order to able to speak, every person needs to communicate intensively practice especially for Indonesia learners who learn English as foreign language and they get little exposure with the target language and restricted only in the classroom. Richards and Renandya (2002:32), state that effective oral communication requires the ability to use the language appropriately in social interactions that involves not only verbal communication but also paralinguistic elements of speech such as pitch, stress, and intonation. Moreover, nonlinguistic elements such as gestures, body language, and expressions are needed in conveying messages directly without any accompanying speech. Brown (2001:4) also states that social contact in interactive language functions is a key importance and in which it is not what you say that counts but how you say it what you convey with body language, gestures, eye contact, physical distance and other nonverbal messages. From some statements above, it can be concluded that speaking skill is always related to communication. Speaking skill can be stated as the skill to use the language accurately to express meanings in order to transfer or to get knowledge and information from other speaker in life situation.

Speaking activities can be challenging for the student since they get several problems to use their target language due to the lack of vocabulary mastery, reluctant to speak English, less confident, and mother- tongue interferences.

In order to solve the problems, the teacher has to develop activities or they have to use interesting method, technique or medium during teaching and learning process in the classroom. So that, it can attract the students to be more active in learning English especially in speaking class. One of the media that can be used to teach English is game. Caillois (2010:67) defines a game as an activity that must have the following characteristics: fun (the activity is chosen for its light-hearted character), separate (it is circumscribed in time and place), uncertain (the outcome of the activity is unforeseeable), nonproductive (participation does not accomplish anything useful), governed by rules (the activity has rules that are different from everyday life) and fictitious (it is accompanied by the awareness of a different reality)".

Online at https://journal.universitasbumigora.ac.id/index.php/humanitatis/

DOI $\quad$ : https://doi.org/10.30812/humanitatis.v8i1.1574 
By using game, there is interaction between the players with each other by following certain rules to get the goal. The game can create an atmosphere of learning become fun, fresh, lively, happy, relaxed but still have a conducive learning atmosphere. A medium of learning, such as game has several advantages in teaching and learning because game is something fun to do, something that is entertaining and interesting.

Moreover, to assist and attract students to speak English, the writer was interested to modify a game for university students. The game was plinko game. The game was played on TV game show or carnival event. In this study, the game was called plinko speaking game. Plinko speaking game is a game which uses board, balls and task cards as media to play this game. However, this game is very interesting that can make the player be excited while playing this game. The game also can attract the player be participation in playing this game. Based on discussion above, the aim of this study is to modify A Plinko Speaking Game as a medium in teaching and learning English to encourage university students in learning English, especially in speaking skill.

\section{RESEARCH METHOD}

This study was classified into descriptive method. According to Burns and Grove (2003:201), descriptive research "Is designed to provide a picture of a situation as it naturally happens". It may be used to jifycurrent practice and make judgment and also to develop theories.

Therefore, the writer used literature review in this study. Literature review was done by finding information about the study from the internet like, website, journals, electronic books and the others sources that might assist in the process of making the product.

There were several procedures in modifying a plinko speaking game, namely: Firstly, preparing the equipment and thematerial; then, preparing the material of thetopic cards' themes; then, designing the board; next, designing the board was byusing Adobe Photoshop CC. The board size that the length will be $60 \mathrm{~cm}$, and the width is $40 \mathrm{~cm}$; next, designing the cards (There would be five cards, the cards were determined of fivethemes. They were; my future plans, let's talk about you, how does she/he look like, let's choose one and penalty card. Thesize of the card would be the length 7 centimeters and the width 5 centimeters); then, designing marbles to be balls of plinko speaking; then, printing the card; then, designing the way how to playthe game, next, Doing the evaluation of theproduct at University; and the last, finishing the product design.

Online at https://journal.universitasbumigora.ac.id/index.php/humanitatis/

DOI $\quad$ : https://doi.org/10.30812/humanitatis.v8i1.1574 


\section{FINDINGS AND DISCUSSION}

There were several processes in modifying a plinko speaking game, start from collecting and providing the material up to designing the product. The processes of modifying the product explained as follow:

\subsection{Collecting and Providing the Material}

The content of this game was about speaking skill game which aims to assist and attract the student to speak English communicatively. There were four themes of speaking cards. The player had to answer the question based on the topic about a minute without do pausing more than a second and there was also a penalty card as punishment if the player cannot pass the rule of game. In collecting and providing the tasksto make questions cards are taken from textbooks for higher education,journal, and internet. After the process of collecting takes to make speaking cards and penalty cards have been completed, the next process were collecting material aplinko speaking board game and designing the cards.

\subsection{Procedure of making the product}

There were several procedures those the writer had to doin modifying this product. The explanation of procedures weredescribed briefly as follow:

1. Preparing the equipment and thematerial

The equipment and the material which was used in modifying this product has been explained in the third chapter.The equipment used such as, hardware (Laptop, printer, andtools) and software (Adobe photoshop CC and MozillaFirefox). Meanwhile, thematerial used such as, paper, wood, sticker, market, pencil, ruler, scissor, knife, nails, andmarbles.

2. Preparing materials of the topic cards' theme

The content of cards' theme in this product were appropriates with university lesson. The materials had been used in modifying the cards were cartoon pictures in order to make the card more interesting and would add text as the task of the cards' topic. The topic cards were: let's talk about you, myfuture plans, let's choose one, how does she/he look like andthere is also penalty card. There were ten questions in each task.

a. Let's talk about you card is a card asking about the player's self. What they say in their mind can determine a lot how they think about who they are.The card was green card.

b. My future plans

My future plans card is a card asking about what the player want to do in their future if they

Online at https://journal.universitasbumigora.ac.id/index.php/humanitatis/

DOI : https://doi.org/10.30812/humanitatis.v8i1.1574 
got the same situation like topiccard question. The card wasorange card.

c. Let's choose one

Let's choose one card is a card asking about the player's opinion related tocomparative and superlativeadjective. The student might choose one of the cards they want. The card was red card.

d. How does she/he look like

How does she/he look like card is a card askingabout describing people how they look like with the player's views. The card was blue card.

e. Penalty card

Penalty card is punishment card if theplayer can't answer the topic card or they can't passthe game rule that has been determined. Therefore, theplayer has to take the penalty card as their punishment. The card wasblack card.

3. Designing the board

The board game wasdesigned by using Adobe photoshop CC first before shapingit onto wooden. The board game size was the same like plinko used to make the background of plinko speaking board morestunning. In decorating, the pictures were inserted by usingquick selection tool and move tool.

Next, the name of product was typed on the board game. The board game name was Plinko Speaking that had created by using horizontal type tool and the color type was white-orange. Moreover, the writer also added some sentence to decorate the board background.

Finally, mark for peg of plinoko speaking board wasmade by using brush tool and position of peg same as theplinko speaking board game designed plans at the thirdchapter. The color mark peg was yellow.

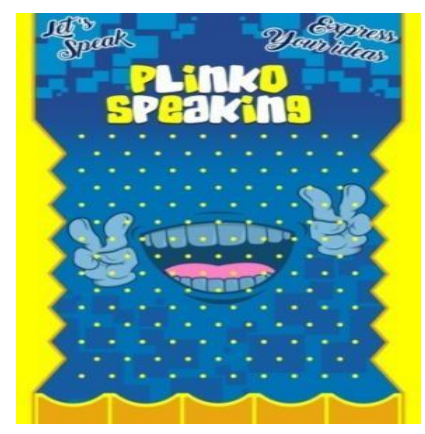

Figure 1. The Result of Plinko Speaking board

The next step, cover of plinkospeaking board was designed. The cover of plinko speaking board was used as the casing of the board game. The design of cover as same as plinko speaking background 
board above and there was name of the product in the center cover.

Then, decoration of background cover was created. In creating the decoration, the writer used rectangle tool and brush tool to create them. At least, the name of product was added in thecenter of cover casing design by using horizontal type tool.

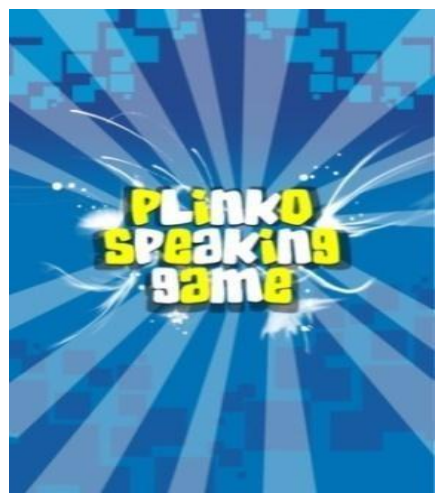

Figure 2. The Result of a Plinko Speaking Cover

After that, a plinko speaking board game was made onto wooden shape. After the material were collected, the next process was making the board by sawing two pieces plywood become $60 \mathrm{cmx} 40 \mathrm{~cm}$ for board and casingof the board game.

Next, the wood was sawn into pieces to make frame of board like the size those were needed. The next, the frame wood of board was painted to make the frame more beautiful. Moreover, the writer used paint dark brown color. Then, all of the material was nailed to make a plinko speaking game board. Finally, pegs of plinko was made.In making the peg, the first process was painting the pegs with yellow color, after that nailed the peg onto plinko speaking board.

1. Designing the small balls of plinko speaking game

The material that used in designing the small ball wasmarbles that would be used for a media to throw poke into the plinko board. In designing the smalls, the first process was painting the marbles with blue color after that, added a plinkospeaking game sticker on the product to decorate it.

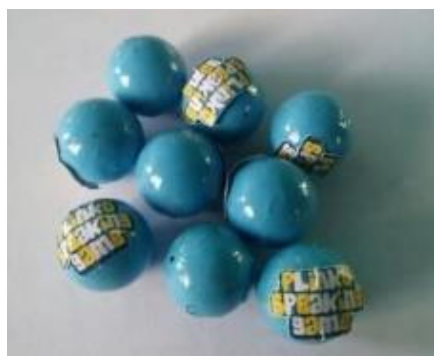

Figure 3. Plinko balls

Online at https://journal.universitasbumigora.ac.id/index.php/humanitatis/

DOI : https://doi.org/10.30812/humanitatis.v8i1.1574 


\section{Designing the card}

Designing the card was also using Adobe photoshopCC. The card size was the length $7 \mathrm{~cm}$ and the width $5 \mathrm{~cm}$. Therewere five kinds of card and each them had difference color cards. The procedures of designing were described as below:

First all, opened adobe Photoshop CC program. And the next step, card background was painted by usingline tool for creating model of decoration and using paint buckettool for gave the color of card.

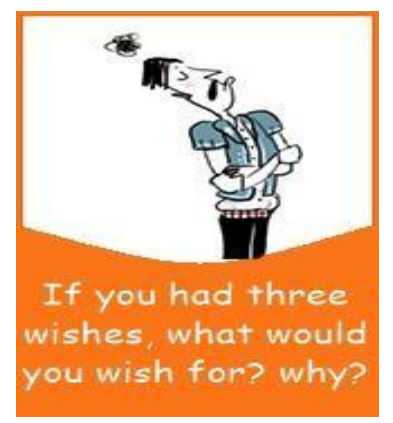

Figure 4. Game Card

After that, the cover of task cards was made. The size and thecolor for cover of task card had the same size and color like the task card. The color and clip art were given on the center asdecoration of the card by using brush paint tool and move tool.

Finally, the card theme wastyped by using horizontal type tool. The color of card cover had the same color like the card task.

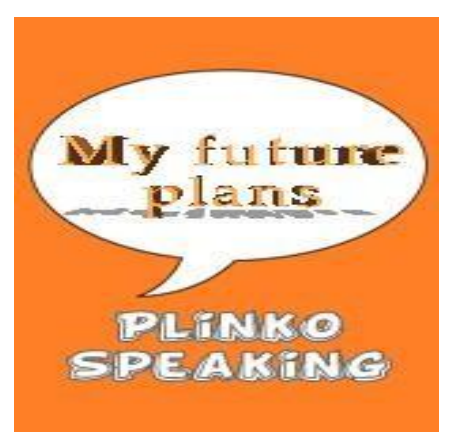

Figure 5. card Cover

For the next cards, there also had the same processes in making the cards. Moreover, the difference cards were the colorand the kind of topic cards. For "Let's talk about you" card the color was green, "Let's chooseone" card the color was red, "How does he/she look like" cardthe color was blue and "Penalty" card the color was black.

Online at https://journal.universitasbumigora.ac.id/index.php/humanitatis/

DOI : https://doi.org/10.30812/humanitatis.v8i1.1574 
5. Printing the cards

After all of the processes making the cards were finished, the next processes were printing the cards that had already finished. The size of cards hadbeen determined. In printing, the writer used printer Canon iP2770and glossy papers.

6. Designing the way how to play the game

The way in playing this game was the same way like the original the way to play this game. This game could be played by a group or an individual. The way played this game and the way how determined the score game those had been explained in the third chapter. In addition,to write the score for each player that used a table in writing that. The contents of table which wereincluded; number of turns, names, score from the teacher which adapted from speaking rubric, score from plinko speaking board and the result from multiplying them. Below was example of scoring

Table 1. The example of table score

\begin{tabular}{|c|c|c|c|c|}
\hline \multirow{2}{*}{ No. } & \multirow{2}{*}{ Name of player } & \multicolumn{2}{|c|}{ Multiplied } & \multirow{2}{*}{ Total } \\
\cline { 3 - 4 } & & Rubric score & Plinko Score & \\
\hline 1. & Isnaini Nurhaya & 3 & 4 & 12 \\
\hline 2. & Zulkarnaen & 4 & 2 & 8 \\
\hline 3. & Dewi Sartika & 2 & 5 & 10 \\
\hline 4. & Jamatul khairiah & 3 & 3 & 9 \\
\hline 5. & Nurjannah & 4 & 2 & 8 \\
\hline
\end{tabular}

7. Doing evaluate of the product at University.

The product had evaluated at State Polytechnic of Bengkalis on Bathin Alam street Sungai Alam. The evaluation was carried out to know whether the product was applicable to encourage the students' speaking ability.

8. Finishing the product design

After evaluated of this product, the next processes were finishing the product design. Finishing the product design was conducted to review the mistake.

The result of this study was a set of A Plinko Speaking Game that consists of board game, task cards and small balls. The decoration of board game was designed by using Adobe PhotoshopCC before create it into wooden shape. The size of the board game was the length $60 \mathrm{~cm}$, the width $40 \mathrm{~cm}$ and it was added $5 \mathrm{~cm}$ for frame of board. This board was domain with blue, white-orange color for the background and casing cover and for decoration of the board. The board was also designed as flexible as possible. It could be seen when the board game was used, the user just had to flip over casing the board and turn it if 
finished. There were five themes of the card as the explanation before and each card has difference color and topic task. However, the similarity was the decoration of the card. The size of card was with the length $7 \mathrm{~cm}$ and the width $5 \mathrm{~cm}$. The small balls were used as media to throw poke into the plinko board. The material that used in designing the small ball was marble. The small balls' color was blue.

After all the processes in modifying the product had been completed, the next process was implementing the product as learning media in speaking class. Both the students and the teacher give positive response to the product. It could be seen from students enthusiast during the learning processes. This product was very good and interesting and the rule how to play the game was effective to be applied in speaking class and may encourage the student to speak spontaneously.

\section{CONCLUSION}

The result of this study was a set of A Plinko Speaking Game that consists of board game, 50 task cards and 10 small balls of plinko speaking game which was provided with the rule how to play the game in speaking class. This learning media can be used to promote students speaking skill especially for college students at the first semester who still reluctant and less confident to speak English during the learning process. The product was effective and interesting to be applied in the class which can be shown by the students' enthusiast in playing the game and their positive response toward the product.

\section{REFERENCES}

Abagail. 2016. Plinko Games for the Classroom of Kindergarten. LasVegas: Nevada.

Arif S. Sadiman,dkk. 2006. Media Pendidikan. Jakarta: RajawaliPers

Burns, N. and Grove, S. K. 2003. The Practice of Nursing Research ( $5^{\text {th }}$ Edition).

Philadelphia: W.B. SaundersCompany.

Brown, H. Douglas. 2001. Language Assessment Principle and Classroom Practice. New York: Longman.

Carter, R. Nunan D. 2001. Teaching English to Speakers of other Languages. Cambridge: Cambridge University Press.

Caillois, Roger. 2010. Les Jeux et lesHommes (games and men). NewYork: Oxford University Press.

Mary J. Allen. 2014. Rubric Workshop Handout: Using Rubrics to Grade, Assess, andImprove Student Learning. The Internet Journal. Retrieved on March $20^{\text {th }}, 2017$ at 10.15 am.

Murrieta, G. and Hernández, E. 2012. Current Research in Teaching and Learning aForeing Language by Graduate Students in Mexico. México: La Editorial Manda.

Online at https://journal.universitasbumigora.ac.id/index.php/humanitatis/

DOI : https://doi.org/10.30812/humanitatis.v8i1.1574 
Richard, J.C. and Renandya, W.A 2002. Methodology in Language Teaching: an Anthology of Current Practice. Cambridge:Cambridge University Press.

Richard, J.C. 2012. Interchange Fourth Edition. Cambridge: Cambridge University Press.

Salen, K. and Zimmerman, E. 2004. Rules of Play: Game Design Fundamentals. Cambridge: The MIT Press.

Token, Sgt. 2005. What is Plinko.Retrieved on $\quad$ November, $17^{\text {th }}, 2016$ at $\quad 9$ am from Http://www.PrizeWheel.com.ht m

Ur,Penny. 2009. A Course inLanguage Teaching Practice. Cambridge: Cambridge University Press.

Zimmer, John. 2012. Manner of Speaking: Rhetoric - The PublicSpeaking Game ${ }^{\mathrm{TM}}$. the internetManner of Speaking Journal.Retrieved on November $19^{\text {th }}, 2016$ at 9 